\title{
The major outer membrane protein OmpU of Vibrio splendidus contributes to host antimicrobial peptide resistance and is required for virulence in the oyster Crassostrea gigas
}

\author{
Marylise Duperthuy ${ }^{1,2,3}$, Johan Binesse ${ }^{4}$, Frédérique Le Roux ${ }^{4,5}$, Bernard Romestand ${ }^{1,2,3}$, Audrey \\ Caro $^{1,2,3}$, Patrice Got $^{1,2,3}$, Alain Givaudan ${ }^{6,7}$, Didier Mazel ${ }^{4}$, Evelyne Bachère ${ }^{1,2,3}$ and Delphine \\ Destoumieux-Garzón ${ }^{1,2,3 \text { * }}$
}

${ }^{1}$ CNRS, UMR 5119, Laboratoire 'Ecosystèmes lagunaires', Université Montpellier 2, 34095

Montpellier, France.

${ }^{2}$ Ifremer and ${ }^{3}$ Université Montpellier 2, Laboratoire 'Ecosystèmes lagunaires', 34095 Montpellier, France.

${ }^{4}$ Institut Pasteur, CNRS, URA 2171, Laboratoire 'Plasticité du génome bactérien', 75015 Paris, France.

${ }^{5}$ Laboratoire de génétique et pathologie, Ifremer, 17390 La Tremblade, France.

${ }^{6}$ INRA and ${ }^{7}$ Université Montpellier 2, Laboratoire 'Ecologie Microbienne des Insectes et Interactions Hôte-Pathogène', 34095 Montpellier, France.

*: Corresponding author : D. Destoumieux-Garzón, Tel. (+33) 4671446 25; Fax (+33) 4671446 22, email address : ddestoum@ifremer.fr

\begin{abstract}
:
Vibrio splendidus, strain LGP32, is an oyster pathogen associated with the summer mortalities affecting the production of Crassostrea gigas oysters worldwide. Vibrio splendidus LGP32 was shown to resist to up to $10 \mu \mathrm{M} \mathrm{Cg}$-Def defensin and $\mathrm{Cg}$-BPI bactericidal permeability increasing protein, two antimicrobial peptides/proteins (AMPs) involved in C. gigas immunity. The resistance to both oyster $\mathrm{Cg}$-Def and $\mathrm{Cg}$-BPI and standard AMPs (polymyxin B, protegrin, human BPI) was dependent on the ompU gene. Indeed, upon ompU inactivation, minimal bactericidal concentrations decreased by up to fourfold. AMP resistance was restored upon ectopic expression of ompU. The susceptibility of bacterial membranes to AMP-induced damages was independent of the ompU-mediated AMP resistance. Besides its role in AMP resistance, ompU proved to be essential for the adherence of $V$. splendidus LGP32 to fibronectin. Interestingly, in vivo, ompU was identified as a major determinant of $V$. splendidus pathogenicity in oyster experimental infections. Indeed, the $V$. splendidus-induced oyster mortalities dropped from $56 \%$ to $11 \%$ upon ompU mutation (Kaplan-Meier survival curves, $\mathrm{P}<0.01$ ). Moreover, in co-infection assays, the ompU mutant was out competed by the wild-type strain with competitive indexes in the range of $0.1-0.2$. From this study, ompU is required for virulence of $V$. splendidus. Contributing to AMP resistance, conferring adhesive properties to $V$. splendidus, and being essential for in vivo fitness, the $O m p U$ porin appears as an essential effector of the $C$. gigas $/ V$. splendidus interaction.
\end{abstract}

Keywords: mollusk, invertebrate, antimicrobial peptide, innate immunity, virulence factor, colonization. 
47 Antimicrobial peptides/proteins (AMPs) are an ancient class of host defense molecules, the presence of 48 which has been reported in almost all living organisms, including bacteria, fungi, plants and animals. 49 AMPs play a central role in the innate immunity of both vertebrates and invertebrates (Sorensen et al., 50 2008). Expressed in phagocytes and epithelial barriers, they are believed to form a first line of defense 51 against invading microbes. AMP structures include $\alpha$-helical peptides (e.g cecropins), disulfide bond52 containing peptides (e.g. defensins), some of which form $\beta$-hairpins (e.g. protegrins, tachyplesins), and 53 peptides with an over-representation of some amino acids (e.g. proline-rich peptides) (Bulet et al., 2004). The 54 amphipathicity and cationic charge of AMPs are considered essential for their binding and insertion into 55 microbial membranes, which are subsequently damaged by pore formation or detergent effect (Brogden, 56 2005).

Contrary to vertebrates, invertebrates lack an acquired immunity based on antibody production.

58 Their defense against microbes is mediated by the so-called innate immunity. With the development of 59 genetic and reverse genetic tools (transgenesis, mutagenesis, RNA interference), AMPs have been 60 shown to play a major role in invertebrate defense. For instance, AMP gene expression could be 61 unambiguously correlated to the resistance to infectious diseases in insects (Lemaitre et al., 1996), 62 nematodes (Alegado and Tan, 2008; Pujol et al., 2008), and crustaceans (de la Vega et al., 2008; de 63 Lorgeril et al., 2008).

Resistance to AMPs is now recognized as an important virulence phenotype in many human 65 pathogenic bacteria. However, with rare exceptions (Derzelle et al., 2004), the resistance to host AMPs 66 has been poorly studied in invertebrate-pathogen interactions. The mechanisms by which pathogenic 67 bacteria escape the host antimicrobial response include the reduction of the net negative charge of the 68 bacterial cell envelope (so that the electrostatic interactions with the cationic AMPs are diminished), the 69 production of bacterial proteases degrading AMPs, and the active efflux of AMPs by drug exporters (for 70 review see (Peschel and Sahl, 2006)). In Vibrio species, AMP-resistance has been mainly studied on the 71 human pathogen $V$. cholerae. Thus, the ompU gene, which encodes a major outer membrane protein, and 72 the vexAB genes, which encode a RND-family efflux system were shown to be involved in the resistance 
73 of $V$. cholerae to polymyxin B or to P2, a synthetic peptide derived from human BPI (Mathur and Waldor, 74 2004; Mathur et al., 2007; Bina et al., 2008).

Several Vibrio splendidus strains have been isolated from oysters during the major summer mortality outbreaks that have affected the Crassostrea gigas production over the past fifteen years (Gay et al., 2004a). Among them, V. splendidus LGP32 was shown to cause mortalities when injected to oysters 78 (Gay et al., 2004b; Le Roux et al., 2007). The genome of V. splendidus LGP32 was sequenced (Le Roux et al., 2009) and genetic tools have been developed that offer the opportunity to decipher the basis of the V. splendidus virulence by the disruption of candidate genes (Le Roux et al., 2007). This led to the

81 identification of the Vsm metalloprotease as a major determinant of toxicity of $V$. splendidus LGP32 extracellular products (ECP) (Binesse et al., 2008). However, the metalloprotease deletion mutant did not display altered virulence in oyster experimental infections (Le Roux et al., 2007).

To face pathogens from their environment, $C$. gigas oysters possess an arsenal of AMPs, which include defensins (Gueguen et al., 2006; Gonzalez et al., 2007a), proline-rich peptides (Gueguen et al., 2009), and a bactericidal/permeability-increasing protein (Gonzalez et al., 2007b), which are concentrated in cells and tissues rather than in a plasma-soluble form. How pathogenic Vibrio species circumvent their host immune response and cause disease is an important question to address. While previous studies have examined the role of $\mathrm{ompU}$ in the adaptation of Vibrio species to environmental parameters such as bile, pH (Wang et al., 2003; Duret et al., 2007; Kao et al., 2009 ), and bacterial AMPs (Provenzano et al.,

91 2001; Mathur and Waldor, 2004), this is the first time, to our knowledge, that the OmpU-mediated AMPresistance is examined in a natural host-Vibrio interaction. Thus, we have examined the role of the outer membrane protein OmpU of the oyster pathogen V. splendidus LGP32 in AMP-resistance and virulence in oysters. To address this question, we have constructed an ompU deletion mutant of $V$. splendidus LGP32, and compared it to the wild-type strain (i) in vitro, in terms of AMP-resistance, through antimicrobial and membrane permeability assays, and (ii) in vivo, in terms of virulence, through standardized experimental infections and colonization assays. Our data show that OmpU contributes to AMP-resistance and is 


\section{Results}

101 Identification of the ompU gene

102 An ompU sequence (VS_2494) similar to that of other Vibrio species was found by homology searches on

103 the chromosome I of Vibrio splendidus LGP32 (Le Roux et al., 2009). The ompU gene encodes a 348

104 amino acid protein (UniProtKB, B7VJI7) presenting 77, 71 and 64\% identities with the OmpU sequences

105 of V. vulnificus (strain CMCP6), V. parahaemolyticus (strain RIMD2210633) and V. cholerae (strain

$106 \mathrm{~N} 16961)$ respectively. The identities with the OmpU sequences of two other $V$. splendidus strains were 87

107 and $79 \%$ for strain $12 \mathrm{~B} 01$ and Med222, respectively. In addition, it displays the conserved site for signal

108 peptidase and the typical Tyr-Asp-Phe (YDF) C-terminal motif (data not shown). After removal of the

109 putative 21-amino acid signal peptide, the OmpU of $V$. splendidus is predicted to be a 327 amino acid-

110 protein with a calculated mass of $35.2 \mathrm{kDa}$ and a theorical pl of 4.19. Synteny analysis with the Magnifying

111 Genome (MaGe) interface (http://www.genoscope.cns.fr/agc/mage) revealed that the genome sequence

112 context surrounding ompU is conserved in many Vibrio species, in particular the marine invertebrate

113 pathogens $V$. harveyi ATCC BAA1116, and V. nigripulchritudo SFn1, whose genome annotation is in

114 progress. Interestingly, neighbor genes encode the penicillin-binding protein 4, DacB (VS_2495), involved

115 in $\beta$-lactam resistance in Pseudomonas aeruginosa (Moya et al., 2009), as well as AcrA (VS_2500) and

116 AcrB (VS_2499), two proteins involved in multidrug efflux in Gram-negative bacteria including

117 Haemophilus influenzae or Enterobacter clocae (Dean et al., 2005 ; Perez et al., 2007) (Figure S1).

118 Those four neighbor genes are conserved in all sequenced Vibrio genomes from the MaGe interface (data

119 not shown).

120

121 Construction of an ompU deletion mutant and ectopic complementation.

122 In order to evaluate the contribution of outer-membrane protein OmpU to the AMP-resistance and

123 virulence of $V$. splendidus LGP32, a $\Delta o m p U$ isogenic mutant was constructed by allelic exchange. A 256-

124 bp sequence ranging from position 517 to 772 was deleted from the ompU sequence. The truncated

$125 \mathrm{OmpU}$ protein deduced from the $\Delta o m p U$ nucleotide sequence is composed of the first 172 amino acids of

$126 \mathrm{OmpU}$ fused to an extra 33 amino acid out-of-frame C-terminal fusion. By subjecting the $\Delta o m p U$ mutant to

127 ectopic complementation, we generated $\triangle o m p U \mathrm{P}_{\mathrm{BAD}}:: \mathrm{omp} U$, in which the ompU gene is under the control 
128 of the arabinose-inducible $\mathrm{P}_{\mathrm{BAD}}$ promotor. The mutant strains were controlled by comparing the wild-type

$129 V$. splendidus LGP32, the $\triangle o m p U$ isogenic mutant and $\triangle o m p U \mathrm{P}_{\mathrm{BAD}}:: \mathrm{ompU}$, for their ompU DNA and RNA

130 content as well as for the presence of $\mathrm{OmpU}$ in an outer membrane protein extract. By PCR amplification,

131 the wild-type and $\Delta o m p U$ Vibrio genomes were shown to carry the full-length and the deleted ompU gene,

132 respectively. As expected, both the full-length and the deleted ompU were evidenced in the

133 complemented strain (Figure 1A). RT-PCR was then performed using primers specific for the amplification

134 of the full-length ompU mRNA, which showed that only the wild-type and complemented strains cultured in

135 the presence of $0.2 \%$ arabinose expressed the full-length ompU (Figure 1B). Finally, the expression of

136 the OmpU protein was observed by SDS-PAGE as a band migrating at $\sim 35 \mathrm{kDa}$ only observed in the

137 outer membrane protein fraction of the wild-type and complemented strains (Figure 1C). Altogether, these

138 data validated the $\Delta o m p U$ mutant and the $\triangle o m p U \mathrm{P}_{\mathrm{BAD}}:: \mathrm{ompU}$ complemented strain at the genomic and

139 expression levels.

140

Fig.1

141 Growth rate of $V$. splendidus LGP32 in oyster plasma is altered by the ompU mutation

142 When observed under a microscope, the $\Delta o m p U$ mutant appeared smaller than the wild-type $V$.

143 splendidus (data not shown). Besides, no detectable growth defect was observed in rich medium. Indeed,

144 the wild-type Vibrio and the $\Delta o m p U$ mutant displayed similar kinetics of growth and final absorbance at

$145600 \mathrm{~nm}$ in Zobell medium (Figure 1D), indicating that the ompU mutation had no deleterious effect in

146 terms of growth. Both strains were then cultured in oyster plasma (cell-free hemolymph), a compartment

147 likely to contain endogenous antimicrobials. While both the wild-type $V$. splendidus LGP32 and the

$148 \Delta$ ompU mutant grew in oyster plasma, the cultures reached a final absorbance at $600 \mathrm{~nm}($ at $16 \mathrm{~h}) \sim 5$

149 times weaker than in Zobell medium (Figure 1D). In addition, the $\Delta o m p U$ mutation significantly altered the

150 Vibrio growth rate (Figure 1D), as indicated by a final absorbance at $600 \mathrm{~nm}$ of $0.285 \pm 0.004$ and $0.211 \pm$

$1510.021(\mathrm{p}<0.05)$, for the wild-type and $\Delta o m p U$ mutant, respectively. Because growth is not prevented but

152 significantly altered, this suggests that $o m p U$ is not required for but contributes to $V$. splendidus resistance

153 to oyster plasma.

154 
157 The wild-type $V$. splendidus LGP32, the $\triangle o m p U$ isogenic mutant, and the $\triangle o m p U \mathrm{P}_{\mathrm{BAD}}:: \mathrm{omp} U$ obtained by

158 ectopic complementation were first exposed to standard cationic antimicrobial peptides (AMPs) and 159 proteins including synthetic protegrin (a $\beta$-hairpin AMP from porcine), synthetic polymixin B ( $\mathrm{PmB}$, a cyclic 160 AMP from bacteria), and recombinant human BPI (hBPI, a large bactericidal protein) in the range of 0.02 $16110 \mu \mathrm{M}$. For all three antimicrobials, minimal bactericidal concentrations (MBCs) measured in PB-NaCl 162 medium were reduced by 2 to more than 4 -fold upon ompU mutation (Table 1 ). The complementation was 163 complete for both protegrin and PmB, and partial for the bactericidal protein hBPI. Thus, the MBC value of $164 \mathrm{hBPI}$, which was above $10 \mu \mathrm{M}$ against the wild-type $V$. splendidus, decreased to $2.5 \mu \mathrm{M}$ upon ompU 165 mutation, and was restored to $5 \mu \mathrm{M}$ upon complementation.

166 We then examined the sensitivity of $V$. splendidus LGP32 to oyster immune effectors, $C g$-Def and $167 \mathrm{Cg}$-BPI. In standard antimicrobial assays, the MBCs of both AMPs were above $10 \mu \mathrm{M}$ (Table 1). We 168 therefore developed a more sensitive assay, the CFU assay, in which bacteria were exposed for $1 \mathrm{~h}$ to 169 increasing AMP concentrations before CFU counting. In the CFU assay, AMP activity is measured in a 170 mineral medium (artificial sea water), preventing the absorption of the AMPs to organic compounds, such 171 as those found in a liquid broth. The actual concentration of AMPs in contact with the bacterial 172 membranes is consequently increased, and the assay is therefore more sensitive. Under such conditions, 173 both $C g$-Def and $C g$-BPI induced a dose-dependent loss of culturability of $V$. splendidus LGP32 (Figure 174 2). Moreover, as with standard AMPs, the CFU counts were systematically lower for the $\Delta$ ompU mutant 175 than for the wild-type and complemented strain (Figure 2). Therefore, the ompU mutation increased the 176 susceptibility of $V$. splendidus to the standard AMPs tested and to the oyster antimicrobials, $C g$-Def and $177 \quad C g$-BPI.

180 Because cationic AMPs are frequently membrane active, we compared the permeability of the 181 membranes of AMP-treated V. splendidus LGP32 in the wild-type strain and $\triangle$ ompU isogenic mutant. 182 Before AMP-treatment, the membrane integrity and functionality of both strains was assessed in three 
183 independent experiments. Stationary phase cultures of the wild-type $V$. splendidus LGP32 and $\Delta o m p U$

184 mutant displayed a similar percentage of cells with intact membranes, i.e. $95.9 \pm 1.8 \%$ and $92.3 \pm 5.0 \%$

185 of propidium iodide (PI)-negative cells, respectively. The respiratory function of the membrane was also

186 similar for both strains with a percentage of cells containing 5 cyano-2,3-ditolyl tetrazolium chloride (CTC)

187 crystals of $89.4 \pm 3.9 \%$ and $90.9 \pm 1.7 \%$, for the wild-type and $\Delta o m p U$ mutant, respectively.

188 Both strains were then exposed for $1 \mathrm{~h}$ to AMPs before staining with PI and Syto9. AMPs were the

189 oyster defensin $\mathrm{Cg}$-Def and tachyplesin, an invertebrate AMP known to induce membrane permeability

190 (Ohta et al., 1992). Both $2 \mu \mathrm{M}$ tachyplesin and $10 \mu \mathrm{M} \mathrm{Cg}$-Def induced major membrane-damages in $V$.

191 splendidus LGP32, as indicated by a high proportion of PI-stained cells $(91.4 \%$ and $99.5 \%$ for $\mathrm{Cg}$-Def and

192 tachyplesin-treated cells, respectively), which were almost absent $(0.2 \%)$ from the untreated control (table

193 2). This showed that, like tachyplesin, the oyster $\mathrm{Cg}$-Def induces inner membrane permeability in $V$.

194 splendidus LGP32. However, the susceptibility of the inner membrane to both AMPs appeared 195 independent of the $\Delta o m p U$ mutation, a similar percentage of PI-stained cells being observed in the AMP-

196 treated samples of the wild-type and $\Delta o m p U$ mutant (table 2).

197

$198 \mathrm{OmpU}$ is required for virulence of $V$. splendidus LGP32 in oyster experimental infections

199 To measure a virulence phenotype of the $\Delta o m p U$ mutation in oysters, we standardized an experimental 200 infection assay (see experimental procedures). Three doses of $V$. splendidus LGP32 wild-type strain ( $2 \mathrm{x}$ $20110^{8} \mathrm{CFU} ; 5 \times 10^{8} \mathrm{CFU} ; 7.5 \times 10^{8} \mathrm{CFU}$ ) were injected per oysters ( $\mathrm{n}=30$ oysters). A significant dose202 dependent effect was observed on oyster mortality (Kaplan-Meier $p<0.01$ ), the LD50 at day 4 (96 h) 203 being obtained for an injection of $5 \times 10^{8} \mathrm{CFU}$ per animal (Figure S2A). The LD50 was then validated in 204 four independent infections (30 oysters each) with $5 \times 10^{8}$ CFU per animal. Kaplan-Meier survival curves 205 were generated proving the lack of statistical difference between the four experiments $(p>0.4)$ and 206 validating our experimental infection assay (Figure S2B).

207 The virulence of the wild-type $V$. splendidus LGP32 and the $\Delta o m p U$ isogenic mutant were then compared 208 by injecting a dose of $5 \times 10^{8} \mathrm{CFU}$ per animal, corresponding to the LD50 for the wild-type strain. Groups 209 of 60 oysters were monitored for 5 days after infection. A major loss of virulence was observed for the $210 \Delta o m p U$ mutant as indicated by the comparison of Kaplan-Meier survival curves $(p<0.01)$ generated for 
211 oysters injected either with the wild-type V. splendidus LGP32 or the $\Delta o m p U$ mutant (Figure 3). Indeed, 212 the mortalities at day 4 were reduced from $56 \%$ for the wild-type strain to $11 \%$ for the $\Delta$ ompU mutant. We 213 then compared the mortalities observed when injecting an identical dose of the $\Delta o m p U$ mutant or a $V$. 214 splendidus-related avirulent control, V. tasmaniensis LMG 20012T. Both strains induced identical 215 mortalities (data not shown).

217 ompU is not required for oyster colonization but confers major competitive colonization advantage to $V$.

218 splendidus LGP32 in oyster experimental infections

219 The ability $V$. splendidus LGP32 wild-type and $\triangle o m p U$ mutant to colonize oyster tissues was monitored 220 over 2 days. When injected separately, both strains colonized oysters to similar extents. Indeed, CFU 221 counts on TCBS plates varied from $4.1 \times 10^{6}$ (day 0 ) to $3.9 \times 10^{4}$ per $\mathrm{g}$ of oyster (day 2) for the wild-type 222 strain, and from $3.4 \times 10^{6}$ (day 0 ) to $4.4 \times 10^{4}$ per g of oyster (day 2) for the $\Delta o m p U$ mutant (Figure $4 \mathrm{~A}$ ). 223 Interestingly, when oysters were co-injected with a 1:1 mixture of the wild-type and $\Delta o m p U$ mutant, the 224 mutant was rapidly out competed by the wild-type Vibrio, with competitive indexes of $0.122 \pm 0.034$ at day 2250 and $0.206 \pm 0.138$ at day 2 (Figure 4B). Interestingly, in vitro competition assays in Zobell medium 226 showed an identical growth of both the wild-type and $\Delta o m p U$ mutant, as indicated by a competitive index 227 of 1 all over the $24 \mathrm{~h}$-time course (data not shown). This indicates that the competitive colonization 228 advantage of the wild-type strain in oyster experimental infections does not result from a toxic effect of the 229 wild-type against the mutant, but rather from a clearance by the oyster immune system.

231 OmpU confers adhesive properties to V. splendidus LGP32

232 Puzzled by the competitive colonization advantage of the wild-type strain, we compared the adhesion 233 properties of the wild-type and $\Delta o m p U$ mutant in a fibronectin-binding assay. Results showed that $o m p U$ 234 is required for the binding of $V$. splendidus LGP32 to fibronectin. Indeed, while the wild-type strain bound 235 to fibronectin in a dose-dependent and specific way (no binding to BSA), the $\triangle o m p U$ mutant did not 236 display any specific binding (Figure 5).

\section{Discussion}


239 Results showed that the major outer-membrane protein OmpU of Vibrio splendidus LGP32 contributes to 240 its resistance to antimicrobial peptides (AMPs) including oyster AMPs, and plays a major role in virulence 241 in Crassostrea gigas oysters. This is the first time, to our knowledge, that the OmpU-mediated AMP242 resistance is examined in a natural host-Vibrio interaction.

$243 \quad V$. splendidus LGP32 was shown here to be resistant to rather high doses of oyster AMPs, with $244 \mathrm{MBCs}$ above $10 \mu \mathrm{M}$ for $\mathrm{Cg}$-BPI and $\mathrm{Cg}$-Def in standard antimicrobial assays. Besides, V. splendidus was 245 able to grow in oyster plasma, either due to its resistance to oyster antimicrobials or to insufficient AMP 246 concentrations in oyster plasma. To investigated the role of ompU in AMP-resistance and in virulence in 247 oysters, we constructed a $\triangle o m p U$ mutant of $V$. splendidus LGP32, and found the $\triangle o m p U$ mutation not to 248 modify its growth rate in rich medium (Zobell). Similarly, a large deletion of the $o m p U$ gene did not modify 249 the growth rate of $V$. cholerae (Provenzano et al., 2001) and $V$. anguillarum (Wang et al., 2003). 250 Moreover, the growth of $V$. splendidus in oyster plasma was altered but not prevented upon ompU 251 mutation. Therefore, like ompU is not required for the resistance of $V$. cholerae to human serum 252 (Provenzano et al., 2001), it is not required for but contributes to the resistance of $V$. splendidus to oyster 253 plasma. One possible reason for that is the higher resistance to antimicrobials conferred by ompU to $V$. 254 splendidus LGP32. Indeed, we showed here that ompU confers resistance to recombinant human BPI, 255 which displayed MBC more than 4-fold lower against the $\Delta$ ompU mutant than against the wild-type $V$. 256 splendidus. This supports previous observation by Mathur and Waldor, who reported a higher sensitivity of 257 V. cholerae to P2, a synthetic peptide derived from human BPI, upon ompU mutation (Mathur and Waldor, 258 2004). While contradictory results were reported on the sensitivity of $V$. cholerae ompU mutants to 259 polymyxin B (PmB) (Provenzano et al., 2001; Mathur and Waldor, 2004), a synthetic cyclic peptide 260 naturally produced by prokaryotes, we found here that ompU contributes to PmB-resistance in $V$. 261 splendidus, with MBCs twice lower against the mutant than against the wild-type and complemented 262 strains. Therefore, together with the $V$. cholerae studies, our results support the role of ompU in the 263 resistance of Vibrio species to cationic antimicrobial peptides and proteins.

264 Interestingly, ompU was also shown to contribute to the resistance to oyster AMPs including $\mathrm{Cg}$-BPI 265 and $\mathrm{Cg}$-Def. While both antimicrobials induced a loss of cultivability of the oyster pathogen, the effect was 266 enhanced upon ompU mutation. To our knowledge, this is the first time the ompU-mediated AMP- 
resistance is studied with the effectors of a natural host-pathogen interaction. However, because ompU 268 conferred only moderate resistance to oyster AMPs as compared to standard cationic antimicrobials, we 269 think that other bacterial genes are required for the resistance of $V$. splendidus to the oyster AMPs. AMP270 resistance may be conferred by the physical nature of the $V$. splendidus cell envelope. Besides, resistance 271 mechanisms may be specific of the $C$. gigas - V. splendidus interaction. Indeed, most infectious microbes 272 are highly adapted to specific hosts, and host cationic AMPs are believed to have co-evolved with 273 microbial resistance (Peschel and Sahl, 2006). However several effectors of AMP-resistance are 274 widespread in the bacterial genomes, some of which are present in V. splendidus LGP32.

275 Thus, one interesting finding from this study is that $o m p U$ belongs to a genomic region that contains 276 several putative effectors of antimicrobial/antibiotic resistance, namely AcrAB (Dean et al., 2005; Perez et 277 al., 2007) (VS_2500 and VS_2499) and the penicillin-binding protein 4, DacB (VS_2495) (Moya et al., 278 2009). Therefore, rather than ompU alone, this synthenic group of genes, which ranges from ompU to 279 acrA and which is conserved among Vibrio species, is likely involved in the resistance of $V$. splendidus to 280 AMPs. Besides, homologues of AMP-resistance genes were found elsewhere in the genome of $V$. 281 splendidus LGP32 and may participate to AMP-resistance in this species. These include (1) vexAB 282 (VS_0064 and VS_0063), which encode resistance/nodulation/division efflux pumps conferring AMP283 resistance in Neisseria gonorrhoeae (Shafer et al., 1998) and Vibrio cholerae (Bina et al., 2008), and (2) 284 phoPQ (VS_0031 and VS_0030), a conserved two component regulatory system mediating AMP285 resistance in many species including Salmonella enterica sevovar Typhimurium (Miller et al., 1990), 286 Pseudomonas aeruginosa (Macfarlane et al., 1999), or Photorhabdus luminescens (Derzelle et al., 2004). 287 How OmpU participates to AMP-resistance in $V$. splendidus LGP32 remains to be established. We 288 showed here that like tachyplesin, the oyster defensin $\mathrm{Cg}$-Def induces severe damages of the $V$. 289 splendidus membranes. However, both peptides induced similar membrane permeability in a wild-type or $290 \Delta o m p U$ background. Similarly, the ompU mutation did not alter the susceptibility of $V$. cholerae outer 291 membrane to the BPI-derived P2 peptide (Mathur and Waldor, 2004). Both studies support the idea that 292 membrane damages are not sufficient to explain the antimicrobial activity of AMPs, and as a 293 consequence, to explain the OmpU-mediated AMP-resistance. We found here that the OmpU proteins 294 from V. splendidus and V. cholerae are 64\% identical and display the conserved C-terminal YXF motif 
proposed to signal the envelope stress response through DegS activation (Walsh et al., 2003). Therefore,

296 as in V. cholerae (Mathur et al., 2007; Davis and Waldor, 2009), OmpU may signal the envelope stress 297 response in $V$. splendidus exposed to cationic AMPs. Indeed, the genes encoding proteins that signal the 298 response to cationic AMPs in V. cholerae (Mathur et al., 2007) are present in the genome of $V$. splendidus 299 LGP32. These include rpoE (VS_2625), which encodes the extracytoplasmic stress factor $\sigma^{\mathrm{E}}$, rseA 300 (VS_2624), which encodes the anti-sigma factor RseA, and degS (VS_0425), which encodes the protease 301 cleaving RseA, thereby releasing $\sigma^{\mathrm{E}}$ (for review see (Ades, 2008)). The very anionic calculated isoelectric 302 point $(\mathrm{pl}=4.19)$ of $V$. splendidus OmpU protein makes it a good candidate for sensing cationic AMPs 303 attracted by the negative net charge of Vibrio outer membranes. Upon interaction with AMPs, OmpU may 304 expose its YDF motif, thereby activating DegS, and cell surface repair mechanisms.

305 Finally, one major finding from this study is that $o m p U$ is essential for the virulence of $V$. splendidus 306 LGP32 in oysters. To our knowledge, this is the first mutation described that induces a loss of virulence in 307 an oyster pathogenic Vibrio. Indeed, deletion of metalloprotease genes drastically lowered the toxicity of 308 Vibrio ECPs but did not alter the virulence in oyster experimental infections (Le Roux et al., 2007 ; 309 Hasegawa et al., 2008). Like in V. splendidus LGP32, OmpU was previously reported to be required for 310 virulence in V. vulnificus, with a 10 fold-increased LD50 in mice upon ompU mutation (Goo et al., 2006). 311 Conversely, OmpU was not essential for V. anguillarum to cause disease in fish (Wang et al., 2003). Our 312 data showed that the loss of virulence of the $\Delta o m p U$ mutant did not result from an inability to colonize the 313 host but corresponded to a marked disadvantage in competitive colonization assays, with competitive 314 indexes $(\mathrm{Cl})$ in the range of $0.11-0.20$. Such a loss of competitivity was also observed for $V$. cholerae in 315 infant mouse intestine colonization, when deleted from the ompU paralogue $v c a 1008(\mathrm{Cl}=0.025)($ Osorio 316 et al., 2004), whereas in similar competition assays, a large deletion of $o m p U$ itself did not severely alter 317 the in vivo competitivity of $V$. cholerae $(\mathrm{Cl}=0.56)$ (Provenzano et al., 2001). Noteworthy, since the ompU 318 mutation had no effect on the in vitro fitness of $V$. splendidus LGP32 $(\mathrm{Cl}=1)$, the rapid clearance of the $319 \Delta o m p U$ mutant in competitive colonization assays is not due to a toxic effect of the wild-type over the 320 mutant but rather to host defense effectors induced in co-infection assays. Together with its role in AMP321 resistance, this shows that $\mathrm{OmpU}$ is an essential determinant of the C. gigas / V. splendidus interaction. 
While the molecular basis of the severe loss of virulence and in vivo competitity of $V$. splendidus upon ompU mutation remain to be established, several hypotheses can already be made. On the one 324 hand, the ompU mutation may alter the expression of virulence factors, although data on $V$. cholerae do 325 not support this hypothesis (Provenzano et al., 2001). On the other hand, this study showed that OmpU 326 has a dual role in (1) resistance to host defenses (oyster plasma and antimicrobials), and (2) host 327 recognition (fibronectin-adhesive properties). On that basis, we think that the loss of competitivity of the $328 \Delta o m p U$ mutant in co-infection assays could be attributed to host defenses induced by the wild-type strain 329 and primarily active against the $\Delta o m p U$ mutant. Indeed, as in V. vulnificus (Goo et al., 2006) and V. 330 cholerae (Sperandio et al., 1995), the OmpU of V. splendidus LGP32 was found here to a ligand of 331 fibronectin, one major extracellular matrix component of mammalian cells. Like mammalian fibronectin, the 332 extracellular $\mathrm{Cg}$-ECSOD of oysters possesses an RGD motif and co-localizes with a beta-integrin-like 333 receptor of hemocytes (Gonzalez et al., 2005). The ompU-mediated adhesive properties of $V$. splendidus 334 LGP32 could therefore be of prime importance in non-self recognition. Such a role of ompU is host 335 recognition is also supported by its major role in avoiding the adherence of the squid symbiont $V$. fisheri to 336 its host hemocytes (Nyholm et al., 2009). Altogether, this identifies OmpU as a key determinant of the $C$. 337 gigas / V. splendidus interaction. Future studies on this host-pathogen interaction will help deciphering the 338 molecular basis of the ompU-mediated virulence of $V$. splendidus in C. gigas oysters.

\section{$340 \quad$ Experimental procedures}

$341 \quad$ Bacterial strains, plasmids and media

342 The bacterial strains and plasmids used in this study are described in Table 3. Escherichia coli strains 343 were grown in Luria-Bertani (LB) or, for strain $\square 3813$, Mueller-Hinton (MH) broth, at $37^{\circ} \mathrm{C}$. Vibrio strains 344 were grown either in LB medium (Difco) supplemented with $\mathrm{NaCl} 0.5 \mathrm{M}$ (LB NaCl), artificial sea water 345 (ASW) (Saulnier et al., 2000) supplemented with $4 \mathrm{~g} / \mathrm{l}$ bactopeptone and $1 \mathrm{~g} / \mathrm{l}$ yeast extract (referred to as 346 Zobell medium), or TCBS (Difco) at $20^{\circ} \mathrm{C}$. Chloramphe nicol $(12.5 \mathrm{mg} / \mathrm{l})$, Thymidine $(0.3 \mathrm{mM})$ and 347 diaminopimelic acid (DAP) $(0.3 \mathrm{mM})$ were added as supplements when necessary. Induction of $c c d B$ 
expression under the control of $\mathrm{P}_{\mathrm{BAD}}$ promoter was achieved by the addition of $0.2 \% \mathrm{~L}$-arabinose to the

349 growth media, and conversely, this activity was repressed by the addition of $1 \%$ D-glucose.

\section{Vector construction for ompU deletion and ectopic complementation}

352 The $\Delta o m p U$ mutant was constructed by allelic exchange using the suicide vector pSW4426T described 353 previously (Le Roux et al., 2007). Briefly, this vector contains the pir-dependent R6K replicative origin, and 354 can be transferred by RP4-based conjugation to $V$. splendidus. It also carries the plasmid $\mathrm{F}$ toxin gene $355(c c d B)$ gene under the control of the $\mathrm{P}_{\mathrm{BAD}}$ promoter. This genetic system allows the efficient counter356 selection of integrated plasmids in the presence of arabinose in $V$. splendidus. The $V$. splendidus ompU 357 gene was PCR-amplified from $V$. splendidus LGP32 genomic DNA using primers 2494-1 and 2494-2, 358 which contains an EcoR1 site at 5' end (table 3). The resulting amplicon (848 bp) was digested by EcoR1 359 and the digestion product (816 bp) was cloned into the EcoR1 site of pUC18 (Pharmacia). An ompU allele 360 carrying an internal deletion ( $\triangle \mathrm{Oomp}()$ was obtained by inverse PCR using the primers 2494-3 and 2494-4 361 (table 3), which contain Xhol sites at 5' ends, and the pUC18 derivative as a template. The PCR product 362 was finally digested with $\mathrm{Xhol}$ and self-ligated. The resulting $\triangle \mathrm{AompU}$ allele was recovered from pUC18 by 363 EcoRI digestion (566 bp) and gel extraction, and introduced by ligation into pSW4426T previously 364 linearized with EcoRI. This led to $\mathrm{pSW} \square 2494 \mathrm{~T}$.

365 Ectopic complementation of the $\mathrm{ompU}$ mutation was performed by introducing the ompU gene into 366 the genome of $V$. splendidus LGP32 $\triangle o m p U$ under the control of the $\mathrm{P}_{B A D}$ promoter. Insertion was 367 targeted to a non-essential multi-copy gene encoding the ISVisp1 transposase, using the strategy 368 previously described (Le Roux et al., 2007). The plasmid was generated by a two-step PCR construction 369 (Matsumoto-Mashimo et al., 2004). The araC-pBAD and ompU genes were PCR-amplified independently 370 using the primer pairs 2494-9 / 2494-10 (1267 bp), and 2494-11 / 2494-12 (1044 bp), respectively (table

371 3). After gel purification, $100 \mathrm{ng}$ of the two PCR products were mixed and a final PCR amplification was 372 carried out using the most external primer pairs 2494-9 and 2494-12, which contain Xho1 sites at 5' ends. 373 After gel purification, the PCR product, referred to as the araC-pBAD::ompU, was Xho1 digested and 374 ligated into the $\mathrm{Xhol}$ site of ISVisp1 orfBAallele carried by pSW86720T. This led to pSW86720T-ompU. 
376 sequencing, both plasmids were transferred to E. coli $\beta 3914$ donor cells. The conjugation experiments

377 with $V$. splendidus strains were performed according to the filter-mating procedure using a donor/recipient 378 ratio of $1 / 10$ as previously described (Le Roux et al., 2007). Selection against the $\square$ dapA donor E. coli $379 \quad \beta 3914$ was achieved by plating onto LB NaCl medium devoid of DAP, and supplemented with $1 \%$ glucose 380 and $12.5 \mathrm{mg} / \mathrm{l}$ chloramphenicol. Antibiotic-resistant colonies were grown in LB $\mathrm{NaCl}$ medium and spread 381 on plates containing $0.2 \%$ arabinose, and screened by PCR-amplification using the primer pair: $2494-5$ et 382 2494-6, which amplify a $616 \mathrm{bp}$ - and a $365 \mathrm{bp}$-fragment on the wild-type and $\Delta o m p U$ strain, respectively.

383 To validate the mutant and complemented strains at the expression level, an RT-PCR was also performed 384 on total RNAs isolated with Trizol reagent (Invitrogen) from stationary phase grown cultures containing $3850.2 \%$ arabinose. The M-MLV reverse transcriptase was purchased from Invitrogen. Primers $2494-7$ and 386 2494-8 specifically amplified the wild type ompU allele (177 bp PCR product), primer 2498-8 being 387 designed in the deleted region of ompU.

389 Animals and hemolymph collection

390 Adult diploid Crassostrea gigas were purchased from a local oyster farm in Mèze (Gulf of Lion, France). 391 When needed, hemolymph was collected by withdrawing 1 to $2 \mathrm{ml}$ from the posterior adductor muscle 392 sinus using a $2 \mathrm{ml}$ syringe equipped with a 23G-needle. Cell-free hemolymph (plasma) was obtained by 393 centrifugation $\left(1,000 \times \mathrm{g}, 15 \mathrm{~min}, 4^{\circ} \mathrm{C}\right)$ and passage of the supernatant throu gh a $0.22 \mu \mathrm{m}$-pore size filter.

\section{Standardized experimental infections}

396 Before an infection, oysters were maintained for 4 days in tanks of UV-treated and biologically filtered sea 397 water. The temperature was maintained at $16^{\circ} \mathrm{C}$ and a $\mathrm{n}$ air-bubbler was added. After 4 days, the 398 culturable endogenous Vibrio species were stabilized at $\sim 100$ colony forming units (CFU) / $\mathrm{ml}$ of oyster 399 hemolymph and $200 \mathrm{CFU} / \mathrm{g}$ of oyster tissue, as estimated on TCBS plates. To allow the intramuscular 400 injection of bacteria, a cut was made in the oyster shell next to the adductor muscle. Bacteria were 401 prepared as follow. V. splendidus LGP32 wild-type and $\Delta o m p U$ as well as the $V$. splendidus-related strain 
402 V. tasmaniensis LMG20012 ${ }^{\top}$ (Thompson et al., 2003), used as an avirulent control (Binesse et al., 2008), 403 were grown overnight at $20^{\circ} \mathrm{C}$ in Zobell medium and $w$ ashed 3 times by centrifugation $(10 \mathrm{~min}, 1,000 \times \mathrm{g}$, $4042^{\circ} \mathrm{C}$ ) in sterile sea water (SSW) obtained by autocl aving. For every experimental infection, 30 oysters 405 were injected at day 0 with $5 \times 10^{8}$ CFU (colony forming unit) /animal under $100 \mu \mathrm{l}$. SSW (100 $\left.\mu \mathrm{l}\right)$ was 406 used as a control. Oysters were placed in 50 liter glass tanks (30 animals / tank). Those tanks were 407 equipped with biological filters and sea water was thermo-regulated at $20^{\circ} \mathrm{C}$. Mortalities were monitore $\mathrm{d}$ 408 daily over five days. The non-parametric Kaplan-Meier test was used to estimate Log-Rank and Wilcoxon 409 values for comparing the survival curves (Kaplan and Meier, 1958). A confidence limit of $95 \%$ was used to 410 test the significance of differences between groups. All experimental infections were performed according 411 to the Ifremer animal care guideline and policy.

\section{Colonization and competition assays}

414 Experimental infections were performed as above. At day 0 (i.e. $1 \mathrm{~h}$ post-injection), and day 2 (48 h p.i.), 6 415 oysters were separately grinded in sterile sea water using an Ultra Turax T25 homogenizer, and serial 416 dilutions were plated onto TCBS plates. CFU were counted after $48 \mathrm{~h}$ at $20^{\circ} \mathrm{C}$. To distinguish wild-type 417 and $\Delta o m p U$ mutants of $V$. splendidus LGP32 from the natural Vibrio species of oysters, colonies isolated 418 from every grinded oyster were analyzed by PCR using primers 2494-9 and 2494-10 designed in LGP32419 specific regions of the $o m p U$ sequence, which encompass the $\Delta o m p U$ deletion. The amplicon size on the 420 V. splendidus LGP32 ompU and $\triangle$ ompU genomic DNA was $732 \mathrm{bp}$ and $382 \mathrm{bp}$, respectively. Primer 421 specificity for the ompU sequence of $V$. splendidus LGP32 was assessed by the lack of amplification on 422 genomic DNAs extracted from 8 different Vibrio strains, including other $V$. splendidus species. We also 423 verified the absence of $V$. splendidus LGP32 in control oysters injected with sterile sea water. In vivo competition assays were performed by simultaneous injection of wild-type $V$. splendidus 425 and $\Delta o m p U$ mutant to oysters. Again, $100 \mu \mathrm{l}$ of a mixture containing $2.5 \times 10^{8} \mathrm{CFU}$ of each strain $(1: 1$ 426 ratio) was injected per animal. At day 0 and day 2, 4 oysters were grinded as above and serial dilutions 427 were plated onto TCBS. Wild-type $V$. splendidus LGP32 were distinguished from the $\triangle$ ompU mutants in 428 every grinded oyster by subjecting 30 randomly selected colonies to the PCR procedure described above. 
429 Competitive index (C.I.) was calculated as the ratio of wild-type to mutant in the input divided by the ratio 430 of wild-type to mutant in the output.

431 In vitro competition assays were performed as follows. Co-cultures were performed in Zobell 432 medium inoculated with $5 \times 10^{4} \mathrm{CFU} / \mathrm{mL}$ of the wild-type and $\Delta$ ompU mutant, and grown over $24 \mathrm{~h}$ at $43320^{\circ} \mathrm{C}$. CFU were counted by plating onto Zobell plate s at $0,15 \mathrm{~min}, 1 \mathrm{~h}, 5 \mathrm{~h}, 8 \mathrm{~h}$, and $24 \mathrm{~h}$. Wild-type $V$. 434 splendidus LGP32 were distinguished from the $\triangle o m p U$ mutants oyster by subjecting 30 randomly selected 435 colonies to the PCR procedure described above. C.I. were calculated as above.

\section{Preparation of outer membrane proteins}

438 Cultures in stationary phase of growth were prepared in Zobell medium containing $0.2 \%$ arabinose. Cells centrifugation (15 min at 3,000 g), cells were resuspended in in $200 \mathrm{mM}$ Tris- $\mathrm{HCl} \mathrm{pH} 8$ containing $1 \mathrm{M}$

441 sucrose, $10 \mathrm{mM}$ EDTA, and $1.5 \mathrm{mg} / \mathrm{ml} \mathrm{lysozyme.} \mathrm{After} 30 \mathrm{~min}$ at $4^{\circ} \mathrm{C}$, cells (spheroplasts) were eliminated 442 by centrifugation ( $15 \mathrm{~min}$ at $16,000 \mathrm{~g}$ ). A fraction containing outer membrane proteins was obtained by 443 ultracentrifugation of the supernatant ( $1 \mathrm{~h}$ at $40,000 \mathrm{~g})$. The protein concentration in the outer membrane 444 protein fraction was estimated using the Bradford method with Micro-BCA protein assay reagent (Pierce 445 Biotechnology, Rockford, IL). Outer membrane proteins were separated on a $15 \%$ sodium dodecyl 446 sulfate-polyacrylamide gel and stained with silver nitrate.

$448 \quad$ Antimicrobial peptides and proteins

449 Recombinant expression and purification of $C$. gigas antimicrobials, namely the $C g$-Def defensin, and the $450 \mathrm{Cg}$-BPI, bactericidal/permeability increasing protein was performed as described previously (Gueguen et 451 al., 2006; Gonzalez et al., 2007b). Recombinant human BPI (hBPI $\left.{ }_{23}\right)$ was a generous gift from Ofer Levy. 452 Chemical synthesis of standard antimicrobial peptides including polymyxin B, tachyplesin and protegrin-1 453 was performed on an Abimed AMS 422 synthesizer by Fmoc chemistry as previously described (Gueguen 454 et al., 2009). 
Minimal Bactericidal Concentrations (MBCs) - Liquid growth inhibition assays (Hetru and Bulet, 1997)

458 were performed in Poor Broth medium supplemented with $0.5 \mathrm{M} \mathrm{NaCl}$ (PB-NaCl, $1 \%$ bactotryptone, $0.5 \mathrm{M}$

$459 \mathrm{NaCl} \mathrm{w} / \mathrm{v}, \mathrm{pH} 7.5)$. Growth was monitored spectrophotometrically at $620 \mathrm{~nm}$ for $24 \mathrm{~h}$ at $20^{\circ} \mathrm{C}$ on a

460 Multiscan microplate reader colorimeter (Dynatech) and the $100 \mu \mathrm{l}$-content of wells displaying no apparent

461 growth was plated onto Zobell agar plates to monitor the loss of cell culturability. MBC values were

462 determined after $48 \mathrm{~h}$ at $20^{\circ} \mathrm{C}$ as the lowest concent ration of peptides at which no CFU could be detected.

463 CFU assay - Peptide activity on cell culturability was assayed in sterile ASW. Bacteria were grown to 464 stationary phase in Zobell medium, washed three times in ASW and adjusted to an input concentration of $46510^{6} \mathrm{CFU} / \mathrm{ml}$. The bacterial suspensions $(100 \mu \mathrm{l})$ were then incubated for $1 \mathrm{~h}$ at $20^{\circ} \mathrm{C}$ with 0.1 to $10 \mu \mathrm{M}$ 466 peptide $(10 \mu \mathrm{l})$ in ASW. Controls were performed for every culture in the absence of peptide (10 $\mu \mathrm{l}$ of 467 water). After incubation, serial dilutions of the bacterial suspensions were plated onto Zobell agar plates 468 and incubated for $24 \mathrm{~h}$ at $20^{\circ} \mathrm{C}$ until colonies were counted.

\section{Fibronectin-binding assay}

471 The wild-type $V$. splendidus and $\Delta o m p U$ isogenic mutant were tested in the fibronectin cell adhesion 472 assay (3H biomedical, Uppsala, Sweden). Briefly, cultures of wild-type (black bars) and $\Delta o m p U$ (white 473 bars) $V$. splendidus in mid-log phase of growth were serially diluted in Zobell medium. Two hundred $\mu \mathrm{l}$ of 474 each cell suspension (ranging from $3.13 \times 10^{7}$ to $2.5 \times 10^{8} \mathrm{CFU} / \mathrm{ml}$ ) were applied onto the microplate of 475 the fibronectin cell adhesion assay coated either with fibronectin or bovine serum albumine (BSA), a large 476 protein used as a negative control. In the negative controls (BSA), the cell suspensions were adjusted to 477 the highest value $\left(2.5 \times 10^{8} \mathrm{CFU} / \mathrm{ml}\right)$. After a 90 min-incubation at room temperature, unbound bacteria 478 were washed away with PBS, and fixed for $10 \mathrm{~min}$ in PBS containing $0.1 \%$ glutaraldehyde. Bacteria were 479 then stained following the manufacturer recommendation. The adhesive properties of the two strains were 480 measured as an absorbance at $590 \mathrm{~nm}$ indicative of their binding to fibronectin.

482 CTC reduction assay

483 The CTC (5 cyano-2,3-ditolyl tetrazolium chloride) reduction assay was used as a direct method to assess 484 bacterial respiration (Rodriguez et al., 1992). A $50 \mathrm{mM}$ stock solution of CTC (Polysciences Europe, 
485 Eppelheim) was freshly prepared just before experiment by dissolving the fluorogenic ester in sterile distilled 486 water. The CTC solution was added to the bacterial suspension $\left(10^{6} \mathrm{cells} / \mathrm{ml}\right.$ in ASW) to a final concentration 487 of $4 \mathrm{mM}$ and incubated in the dark for $1 \mathrm{~h}$ at room temperature. CTC reduction was stopped by the addition 488 of formaldehyde ( $4 \%$ final concentration) and stored at $4^{\circ} \mathrm{C}$ until microscopic observation. The fixed Vibrio 489 suspensions previously incubated with CTC were counter-stained with 4'-6-Diamidino-2-phenylindole (DAPI) 490 in Tris- $\mathrm{HCl} \mathrm{pH} 7.1$ for $15 \mathrm{~min}$ in the dark at a final concentration of $2.5 \mathrm{mg} / \mathrm{ml}$. Microscopic observations 491 were performed under an Olympus Provis epifluorescence microscope. Stained cells were captured by 492 microfiltration through a $0.2 \mu \mathrm{m}$-pore size Nucleopore black polycarbonate filter ( $47 \mathrm{~mm}$ diameter). Filters 493 were air-dried and mounted with immersion oil on glass microscope slides. Preparations were examined 494 under immersion with 100 X objective lens. Approximately 500 total bacterial cells were counted. Respiring 495 bacteria were counted with excitation at $420 \mathrm{~nm}$ and total bacteria were counted at $357 \mathrm{~nm}$. The fractions of 496 CTC-positive cells were calculated as the ratio of CTC-positive to DAPI cell counts.

\section{Flow cytometry assessment of membrane permeability}

499 The membrane permeability of the Vibrio strains exposed to antimicrobial peptides was tested by flow 500 cytometry after treatment with the LIVE/DEAD BacLight Bacterial Viability kit (Molecular Probes). Briefly, 501 stationary phase cultures of wild-type and mutant $V$. splendidus were prepared as in CFU assay, and 100 $502 \mu \mathrm{l}$ of the bacterial suspension $\left(10^{7}\right.$ cells $\left./ \mathrm{ml}\right)$ were exposed to $2 \mu \mathrm{M}$ tachyplesin, or $10 \mu \mathrm{M} \mathrm{Cg}$-Def. An 503 equivalent volume of water $(10 \mu \mathrm{l})$ was used in controls. After $1 \mathrm{~h}$ at $20^{\circ} \mathrm{C}, 890 \mu \mathrm{l}$ ASW were added to the 504 bacterial suspension to dilute the peptides. The membrane permeability of the bacteria was monitored as 505 previously published (Passerat et al., 2009) by adding $3 \mu \mathrm{l}$ of a 1:1 (v/v) mixture of SYTO9 and propidium 506 iodide (PI) from the LIVE/DEAD kit to the bacterial suspension ( $1 \mathrm{ml}$ at $\left.10^{6} \mathrm{cells} / \mathrm{ml}\right)$. Incubation was 507 performed for $15 \mathrm{~min}$ in the dark, at room temperature. Flow cytometry analysis were performed on a 508 FACSCalibur (Becton Dickinson, San Jose,Calif., USA), with $488 \mathrm{~nm}$ excitation from a blue laser at 15 $509 \mathrm{~mW}$ argon ion. Analyses were run at low speed $(15 \mu \mathrm{l} / \mathrm{min})$ for a 2 min-acquisition time. The green 510 fluorescence of SYTO9 was measured at $530 \mathrm{~nm}$ (FL1 channel), and the red fluorescence of PI was 511 measured above $670 \mathrm{~nm}$ (FL3 channel). Cells with damaged membrane (PI-positive cells) were 
512 differentiated from those with intact membrane by their signature in a plot of green versus red 513 fluorescence.

\section{Acknowledgements}

516 We are grateful to Laure Sauné, Julie Fievet, Pascal Alonso, and Marc Leroy for precious technical 517 assistance. M.D. received fellowship from the Ifremer (graduate student grant). This work received 518 financial support from Ifremer and CNRS.

\section{References}

Ades, S.E. (2008) Regulation by destruction: design of the sigmaE envelope stress response. Curr Opin Microbiol 11: 535-540.

524 Alegado, R.A., and Tan, M.W. (2008) Resistance to antimicrobial peptides contributes to persistence of Salmonella typhimurium in the C. elegans intestine. Cell Microbiol 10: 1259-1273.

526 Bina, X.R., Provenzano, D., Nguyen, N., and Bina, J.E. (2008) Vibrio cholerae RND family efflux systems are required for antimicrobial resistance, optimal virulence factor production, and colonization of the infant mouse small intestine. Infect Immun 76: 3595-3605.

529 Binesse, J., Delsert, C., Saulnier, D., Champomier-Verges, M.C., Zagorec, M., Munier-Lehmann, H. et al. 530 (2008) Metalloprotease vsm is the major determinant of toxicity for extracellular products of Vibrio splendidus. Appl Environ Microbiol 74: 7108-7117.

532 Brogden, K.A. (2005) Antimicrobial peptides: pore formers or metabolic inhibitors in bacteria? Nat Rev Microbio/ 3: 238-250.

534 Bulet, P., Stocklin, R., and Menin, L. (2004) Anti-microbial peptides: from invertebrates to vertebrates. Immunol Rev 198: 169-184.

536 Davis, B.M., and Waldor, M.K. (2009) High-throughput sequencing reveals suppressors of Vibrio cholerae rpoE mutations: one fewer porin is enough. Nucleic Acids Res. 
de la Vega, E., O'Leary, N.A., Shockey, J.E., Robalino, J., Payne, C., Browdy, C.L. et al. (2008) Antilipopolysaccharide factor in Litopenaeus vannamei (LvALF): a broad spectrum antimicrobial peptide essential for shrimp immunity against bacterial and fungal infection. Mol Immunol 45: 1916-1925.

de Lorgeril, J., Gueguen, Y., Goarant, C., Goyard, E., Mugnier, C., Fievet, J. et al. (2008) A relationship between antimicrobial peptide gene expression and capacity of a selected shrimp line to survive a Vibrio infection. Mol Immunol 45: 3438-3445.

Dean, C.R., Narayan, S., Daigle, D.M., Dzink-Fox, J.L., Puyang, X., Bracken, K.R. et al. (2005) Role of the AcrAB-TolC efflux pump in determining susceptibility of Haemophilus influenzae to the novel peptide deformylase inhibitor LBM415. Antimicrob Agents Chemother 49: 3129-3135.

Derzelle, S., Turlin, E., Duchaud, E., Pages, S., Kunst, F., Givaudan, A., and Danchin, A. (2004) The PhoP-PhoQ two-component regulatory system of Photorhabdus luminescens is essential for virulence in insects. J Bacteriol 186: 1270-1279.

Duret, G., Simonet, V., and Delcour, A.H. (2007) Modulation of Vibrio cholerae porin function by acidic pH. Channels (Austin) 1: 70-79.

Gay, M., Berthe, F.C., and Le Roux, F. (2004a) Screening of Vibrio isolates to develop an experimental infection model in the Pacific oyster Crassostrea gigas. Dis Aquat Organ 59: 49-56.

Gay, M., Renault, T., Pons, A.M., and Le Roux, F. (2004b) Two vibrio splendidus related strains collaborate to kill Crassostrea gigas: taxonomy and host alterations. Dis Aquat Organ 62: 65-74.

Gonzalez, M., Gueguen, Y., Desserre, G., de Lorgeril, J., Romestand, B., and Bachère, E. (2007a) Molecular characterization of two isoforms of defensin from hemocytes of the oyster Crassostrea gigas. Dev Comp Immunol 31: 332-339.

Gonzalez, M., Romestand, B., Fievet, J., Huvet, A., Lebart, M.C., Gueguen, Y., and Bachère, E. (2005) Evidence in oyster of a plasma extracellular superoxide dismutase which binds LPS. Biochem Biophys Res Commun 338: 1089-1097.

Gonzalez, M., Gueguen, Y., Destoumieux-Garzón, D., Romestand, B., Fievet, J., Pugnière, M. et al. (2007b) Evidence of a bactericidal permeability increasing protein in an invertebrate, the Crassostrea gigas Cg-BPI. Proc Natl Acad Sci U S A 104: 17759-17764. 
Goo, S.Y., Lee, H.J., Kim, W.H., Han, K.L., Park, D.K., Lee, H.J. et al. (2006) Identification of OmpU of Vibrio vulnificus as a fibronectin-binding protein and its role in bacterial pathogenesis. Infect Immun 74: 5586-5594.

Gueguen, Y., Romestand, B., Fievet, J., Schmitt, P., Destoumieux-Garzón, D., Vandenbulcke, F. et al. (2009) Oyster hemocytes express a proline-rich peptide displaying synergistic antimicrobial activity with a defensin. Mol Immunol 46: 516-522.

Gueguen, Y., Herpin, A., Aumelas, A., Garnier, J., Fievet, J., Escoubas, J.M. et al. (2006) Characterization of a defensin from the oyster Crassostrea gigas. Recombinant production, folding, solution structure, antimicrobial activities, and gene expression. J Biol Chem 281: 313-323.

Hasegawa, H., Lind, E.J., Boin, M.A., and Hase, C.C. (2008) The extracellular metalloprotease of Vibrio tubiashii is a major virulence factor for pacific oyster (Crassostrea gigas) larvae. Appl Environ Microbiol 74: 4101-4110.

Hetru, C., and Bulet, P. (1997) Strategies for the isolation and characterization of antimicrobial peptides of invertebrates. Methods Mol Biol 78: 35-49.

Kao, D.Y., Cheng, Y.C., Kuo, T.Y., Lin, S.B., Lin, C.C., Chow, L.P., and Chen, W.J. (2009) Salt-responsive outer membrane proteins of Vibrio anguillarum serotype $\mathrm{O} 1$ as revealed by comparative proteome analysis. J Appl Microbiol 106: 2079-2085.

Kaplan, E.L., and Meier, P. (1958) Non parametric estimation for incomplete observations. J. Am. Stat. Assoc. 53: 457-481.

Le Roux, F., Binesse, J., Saulnier, D., and Mazel, D. (2007) Construction of a Vibrio splendidus mutant lacking the metalloprotease gene vsm by use of a novel counterselectable suicide vector. Appl Environ Microbiol 73: 777-784.

Le Roux, F., Zouine, M., Chakroun, N., Binesse, J., Saulnier, D., Bouchier, C. et al. (2009) Genome sequence of Vibrio splendidus: an abundant planctonic marine species with a large genotypic diversity. Environ Microbiol.

Lemaitre, B., Nicolas, E., Michaut, L., Reichhart, J.M., and Hoffmann, J.A. (1996) The dorsoventral regulatory gene cassette spatzle/Toll/cactus controls the potent antifungal response in Drosophila adults. Cell 86: 973-983. 
Macfarlane, E.L., Kwasnicka, A., Ochs, M.M., and Hancock, R.E. (1999) PhoP-PhoQ homologues in Pseudomonas aeruginosa regulate expression of the outer-membrane protein OprH and polymyxin B resistance. Mol Microbiol 34: 305-316.

Mathur, J., and Waldor, M.K. (2004) The Vibrio cholerae ToxR-regulated porin OmpU confers resistance to antimicrobial peptides. Infect Immun 72: 3577-3583.

Mathur, J., Davis, B.M., and Waldor, M.K. (2007) Antimicrobial peptides activate the Vibrio cholerae sigmaE regulon through an OmpU-dependent signalling pathway. Mol Microbio/ 63: 848-858.

600 Matsumoto-Mashimo, C., Guerout, A.M., and Mazel, D. (2004) A new family of conditional replicating plasmids and their cognate Escherichia coli host strains. Res Microbiol 155: 455-461.

Miller, S.I., Pulkkinen, W.S., Selsted, M.E., and Mekalanos, J.J. (1990) Characterization of defensin

Moya, B., Dotsch, A., Juan, C., Blazquez, J., Zamorano, L., Haussler, S., and Oliver, A. (2009) Betalactam resistance response triggered by inactivation of a nonessential penicillin-binding protein. PLoS Pathog 5: e1000353.

Nyholm, S.V., Stewart, J.J., Ruby, E.G., and McFall-Ngai, M.J. (2009) Recognition between symbiotic Vibrio fischeri and the haemocytes of Euprymna scolopes. Environ Microbiol 11: 483-493.

610 Ohta, M., Ito, H., Masuda, K., Tanaka, S., Arakawa, Y., Wacharotayankun, R., and Kato, N. (1992) 611 Mechanisms of antibacterial action of tachyplesins and polyphemusins, a group of antimicrobial peptides isolated from horseshoe crab hemocytes. Antimicrob Agents Chemother 36: 1460-1465.

613 Osorio, C.G., Martinez-Wilson, H., and Camilli, A. (2004) The ompU Paralogue vca1008 is required for virulence of Vibrio cholerae. J Bacteriol 186: 5167-5171.

615 Passerat, J., Got, P., Dukan, S., and Monfort, P. (2009) Respective roles of culturable and viable-but616 nonculturable cells in the heterogeneity of Salmonella enterica serovar typhimurium invasiveness. Appl Environ Microbiol 75: 5179-5185.

618 Perez, A., Canle, D., Latasa, C., Poza, M., Beceiro, A., Tomas Mdel, M. et al. (2007) Cloning, nucleotide 619 sequencing, and analysis of the AcrAB-TolC efflux pump of Enterobacter cloacae and determination 
of its involvement in antibiotic resistance in a clinical isolate. Antimicrob Agents Chemother 51: 3247-3253.

Peschel, A., and Sahl, H.G. (2006) The co-evolution of host cationic antimicrobial peptides and microbial resistance. Nat Rev Microbiol 4: 529-536.

Provenzano, D., Lauriano, C.M., and Klose, K.E. (2001) Characterization of the role of the ToxRmodulated outer membrane porins OmpU and OmpT in Vibrio cholerae virulence. J Bacteriol 183: 3652-3662.

Pujol, N., Zugasti, O., Wong, D., Couillault, C., Kurz, C.L., Schulenburg, H., and Ewbank, J.J. (2008) Antifungal innate immunity in $C$. elegans is enhanced by evolutionary diversification of antimicrobial peptides. PLoS Pathog 4: e1000105.

Rodriguez, G.G., Phipps, D., Ishiguro, K., and Ridgway, H.F. (1992) Use of a fluorescent redox probe for direct visualization of actively respiring bacteria. Appl Environ Microbiol 58: 1801-1808.

Saulnier, D., Avarre, J.C., Le Moullac, G., Ansquer, D., Levy, P., and Vonau, V. (2000) Rapid and sensitive PCR detection of Vibrio penaeicida, the putative etiological agent of syndrome 93 in New Caledonia. Dis Aquat Organ 40: 109-115.

Thompson, F.L., Thompson, C.C., and Swings, J. (2003) Vibrio tasmaniensis sp. nov., isolated from Atlantic salmon (Salmo salar L.). Syst Appl Microbiol 26: 65-69. envelope-stress response by activating DegS protease via relief of inhibition mediated by its PDZ domain. Cell 113: 61-71. 
647 Wang, S.Y., Lauritz, J., Jass, J., and Milton, D.L. (2003) Role for the major outer-membrane protein from 648 Vibrio anguillarum in bile resistance and biofilm formation. Microbiology 149: 1061-1071.

649

650 


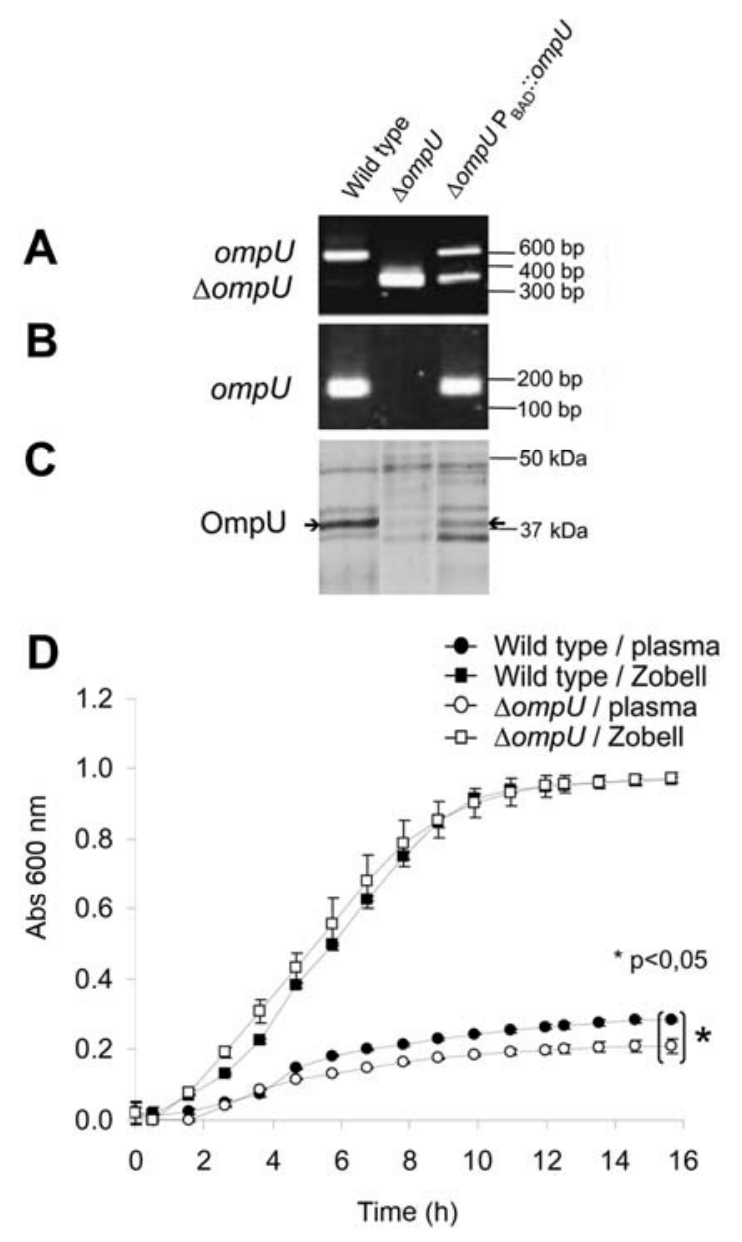

Figure 1. Inactivation of the OmpU protein does not impair the growth of $V$. splendidus LGP32 in

654 Zobell medium and oyster plasma.

655 (A) PCR-amplification of genomic DNA. The $616 \mathrm{bp}$ - and 365 bp-amplicons corresponding to the wild-type 656 (full-length) and the deleted ompU alleles, are observed in the wild-type and $\Delta o m p U$ mutant, respectively.

657 Both alleles are evidenced in the complemented strain. (B) Specific RT-PCR amplification (177 bp) of the 658 full-length ompU mRNA. Amplicons are observed for the wild-type and complemented strains only. (C) 659 Silver-stained SDS-PAGE of outer membrane proteins. The OmpU protein (arrow) is observed for the 660 wild-type and complemented strains, only. (D) Growth of the wild-type (closed symbols) and $\Delta o m p U$ 661 mutant (open symbols) in Zobell medium (boxes) and oyster plasma (circles). No significant difference is 662 observed in Zobell medium, while a significant difference $(p<0.05)$ is observed in plasma. 


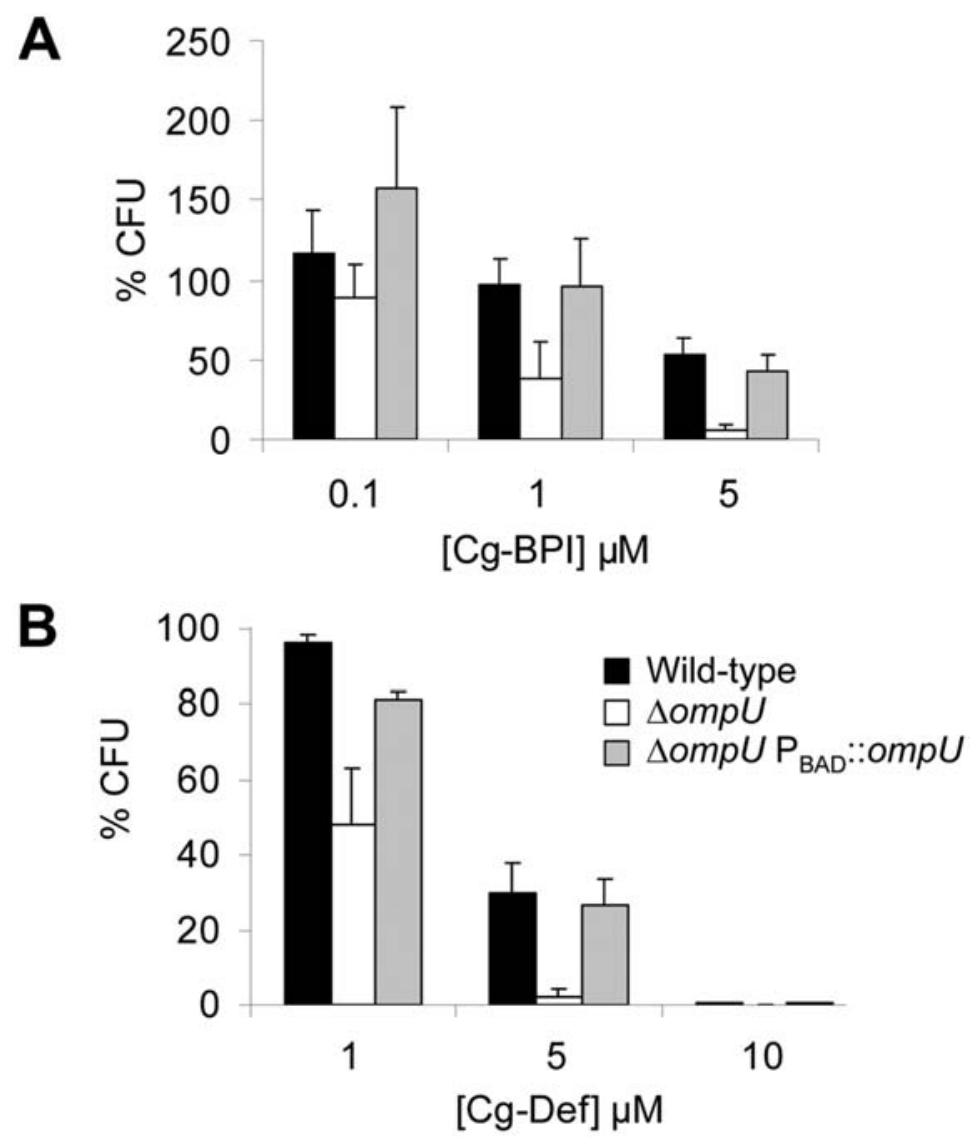

664

Figure 2

665 Figure 2. OmpU contributes to the resistance of $V$. splendidus LGP32 to $\mathrm{Cg}$-BPI and Cg-Def

666 The wild-type $V$. splendidus LGP32, the $\triangle o m p U$ isogenic mutant, and the $\triangle o m p U \mathrm{P}_{\mathrm{BAD}}:: 0 m p U$ obtained by

667 ectopic complementation were exposed to increasing concentrations of $C g$-BPI (A), and $C g$-Def (B), or an

668 equivalent volume of water (controls). CFU were counted after a $1 \mathrm{~h}$-incubation for all three strains. The

669 graph shows the culturability of the wild-type (black rectangles), $\Delta o m p U$ mutant (white rectangles) and the

670 complemented mutant (gray rectangles) as a percentage of the CFU counted in their respective controls

671 without peptide $\left(1.03 \times 10^{5} \pm 4.62 \times 10^{4} \mathrm{CFU} / \mathrm{ml}, 1.03 \times 10^{5} \pm 2.4 \times 10^{3} \mathrm{CFU} / \mathrm{ml}\right.$, and $9.39 \times 10^{4} \pm 3.3 \times 10^{3}$

$672 \mathrm{CFU} / \mathrm{ml}$, for the wild-type, $\Delta o m p U$, and $\triangle o m p U \mathrm{P}_{\mathrm{BAD}}:: \mathrm{ompU}$ controls, respectively). Data are the mean of

673 three independent experiments \pm SEM. 


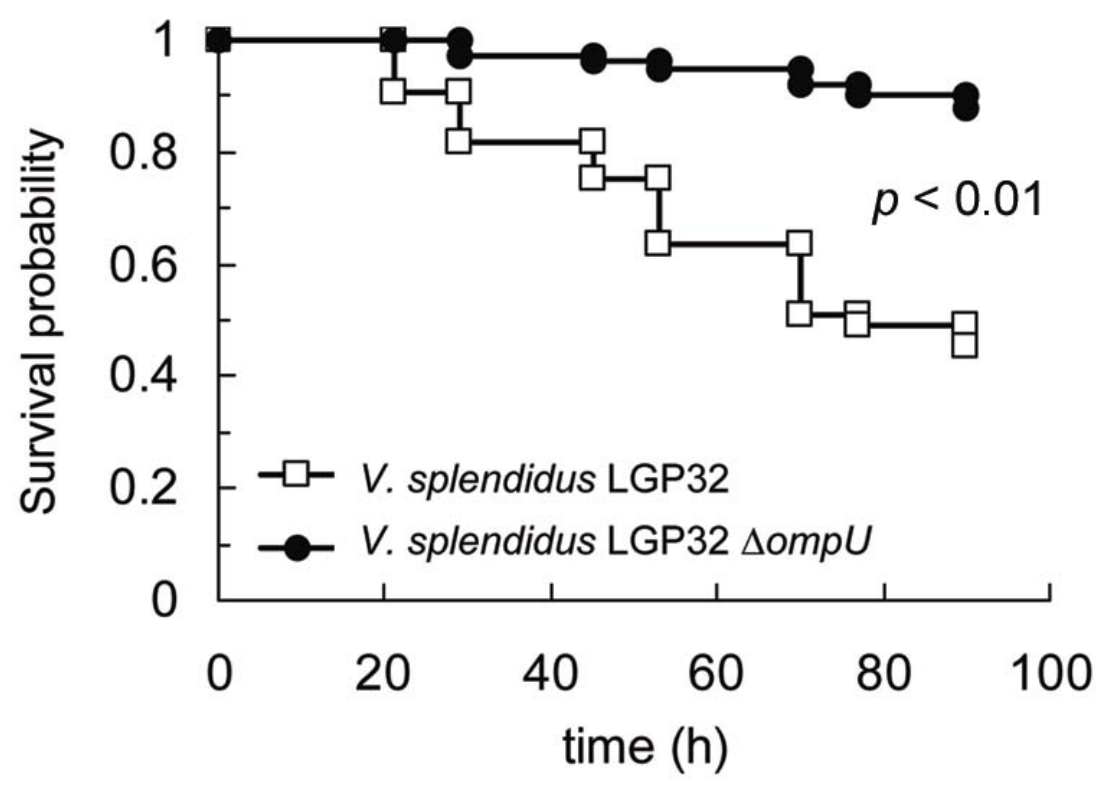

676 Figure 3. Inactivation of ompU results in a loss of virulence of $V$. splendidus LGP32 in oyster 677 experimental infections

678 The wild-type $V$. splendidus LGP32 and the $\Delta o m p U$ isogenic mutant were injected to oysters at a dose of $6795 \times 10^{8} \mathrm{CFU}$ per animal. Groups of 60 oysters were monitored for four days after infection. Kaplan-Meier 680 survival curves were generated for oysters injected with the wild-type V. splendidus LGP32 (open boxes) 681 and the $\Delta o m p U$ mutant (closed circles). Data are representative of three independent survival 682 experiments.

683

684 


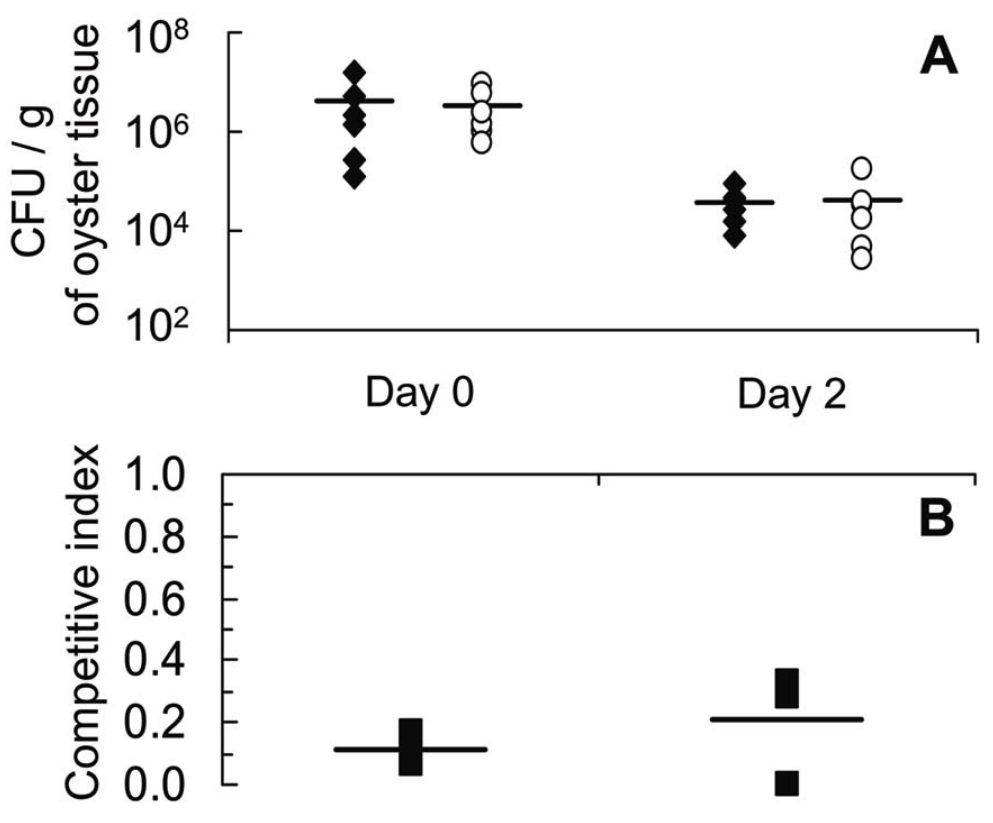

687 Figure 4. The ompU deletion mutant is competed out by wild-type $V$. splendidus LGP32 in oyster experimental infections

689 (A) Six oysters were injected with $5 \times 10^{8}$ CFU of either V. splendidus LGP32 (closed diamonds) or the $690 \Delta o m p U$ isogenic mutant (open circles). CFU were counted in oyster tissues at day 0 and day 2 by plating 691 on TCBS agar plates. Data points represent CFU counted in each oyster, and bars represent the CFU 692 average for the six oysters. (B) Groups of four oysters were co-injected with a 1:1 ratio of a mixture of the 693 ompU mutant and the wild-type $V$. splendidus LGP32 $\left(5 \times 10^{8} \mathrm{CFU}\right.$ per oyster). The competitive index (Cl) 694 of the $\Delta o m p U$ mutant was calculated for every oyster at day 0 and day 2. Plots represent $\mathrm{Cl}$ values in 695 individual oysters and bars represent the average calculated for four oysters. $\mathrm{A} \mathrm{Cl}<1$ indicates 696 domination by $V$. splendidus wild-type strain. 


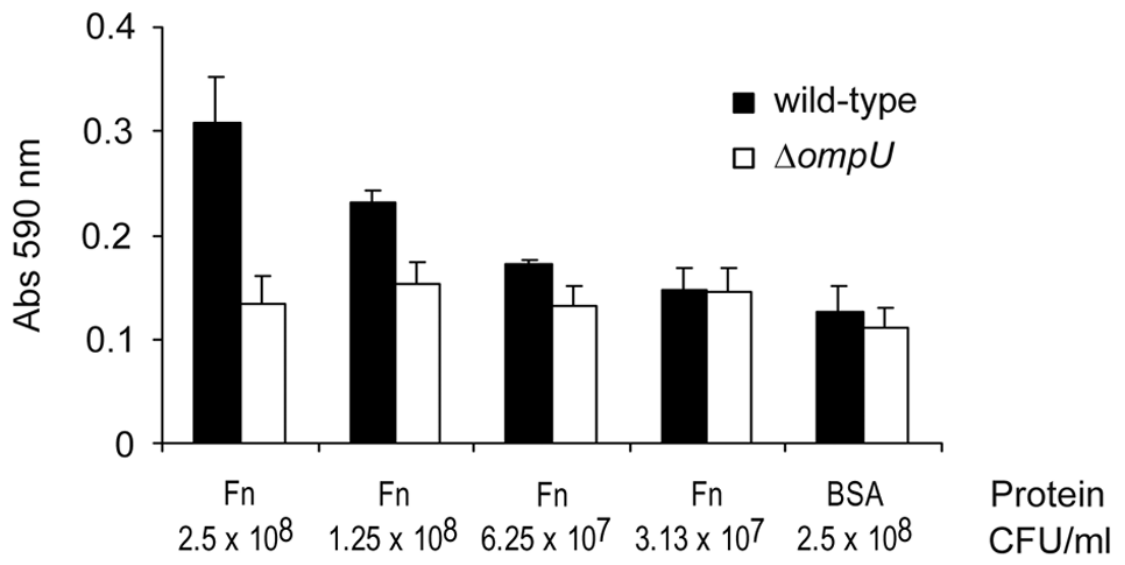

700 Figure 5. ompU confers fibronectin-adhesive properties to V. splendidus LGP32

701 Mid-log phase cultures of wild-type (black bars) and $\Delta o m p U$ (white bars) V. splendidus serially diluted in

702 Zobell medium were subjected to the fibronectin-binding assay. In this assay, the adhesive properties of

703 the two strains are measured by a colorimetry (absorbance at $590 \mathrm{~nm}$ ), which is indicative of their binding

704 to fibronectin (Fn) or bovine serum albumine (BSA), a large protein used as a negative control.

705

706 


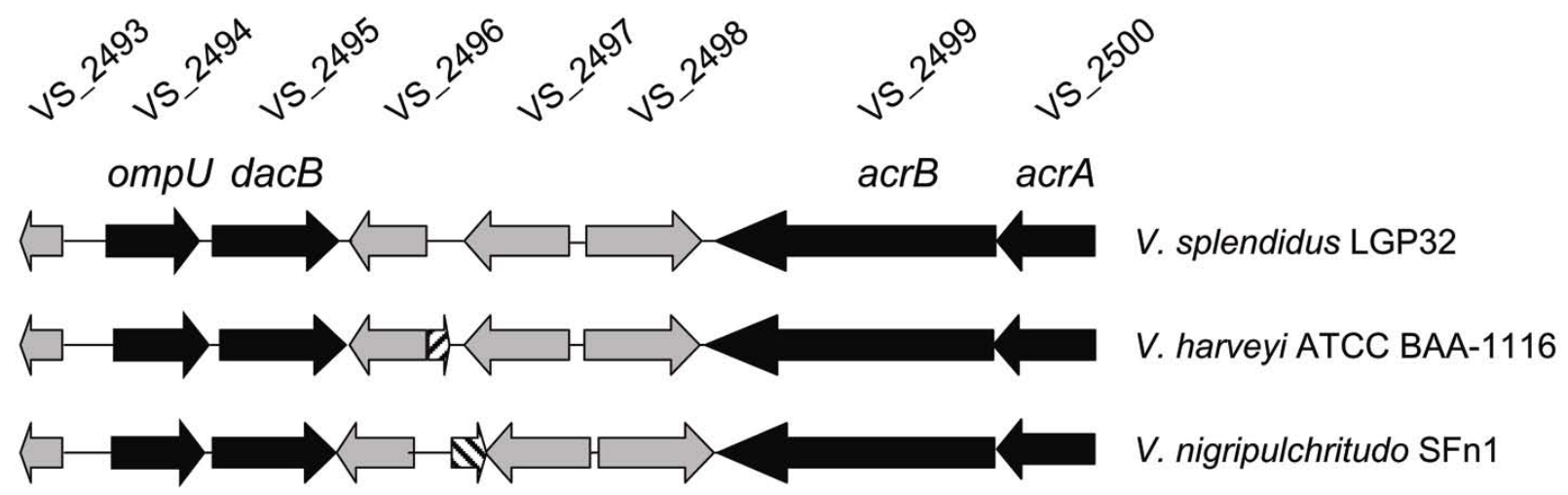

708 Figure S1. Genetic organization of the ompU gene region. The region flanking ompU localized on 709 chromosome 1 of $V$. splendidus LGP32 is compared to the corresponding region on the chromosome 1 of $710 \quad V$. harveyi ATCC BAA-1116 and V. nigripulchritudo SFn1. Gray and black arrows are conserved between

711 the three genetic regions. Dashed arrows refer to genes absent from the genome sequence context 712 surrounding ompU in V. splendidus LGP32. Black arrows refer to genes with a potential role in resistance 713 to antimicrobials/antibiotics. The gene names and labels are displayed above the arrows.

714 

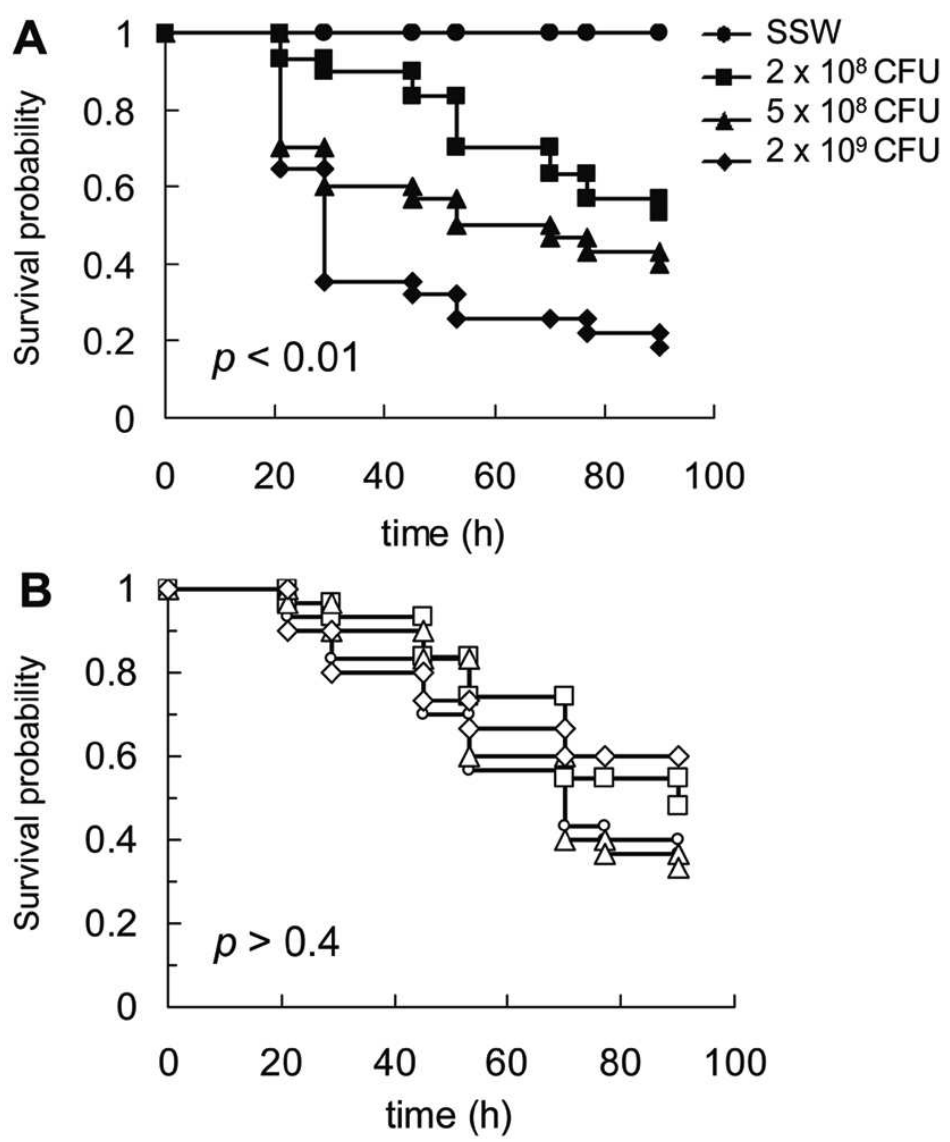

717 Figure S2. Standardization of oyster experimental infections by V. splendidus LGP32

718 (A) Three groups of 30 oysters were injected with wild-type V. splendidus LGP32 at the following doses:

$7192 \times 10^{8}$ (closed boxes), $5 \times 10^{8}$ (closed triangles), or $2 \times 10^{9}$ (closed diamonds) CFU per animal. A control 720 was performed by injection of sterile sea water (SSW, closed circles). Oyster mortalities were monitored 721 over four days and Kaplan-Meier survival curves were generated. (B) The wild-type V. splendidus LGP32 722 was injected to oysters at a dose of $5 \times 10^{8} \mathrm{CFU}$ per animal. Groups of 30 oysters were monitored for 4 723 days after infection. Kaplan-Meier survival curves were generated for four independent survival 724 experiments. A different open symbol was attributed to every of the four replicates. 